\title{
Late-onset hypogonadism in men. Experience from the Turku Male Ageing Study (TuMAS)
}

\author{
Ilpo Huhtaniemi ${ }^{1,4}$, Juuso I. Mäkinen ${ }^{3}$, Antti Perheentupa ${ }^{1,2}$, Olli T. Raitakari ${ }^{3}$ \\ ${ }^{1}$ Department of Physiology, ${ }^{2}$ Obstetrics and Gynaecology, ${ }^{3}$ Clinical Physiology, University of Turku, Turku, Finland, \\ ${ }^{4}$ Department of Reproductive Biology, Imperial College London, London, UK
}

\begin{abstract}
Interest has arisen during the last 10 years as to the possible connection between the age-related decline in androgen production and symptoms of ageing in men. A new ageing-related syndrome with several descriptive names, such as andropause, male menopause, Partial Androgen Deficiency of the Ageing Male (PADAM) and Late-Onset Hypogonadism (LOH), has been identified. Intensive research into the subject is currently ongoing in multiple, population-based epidemiological studies to explore the connections between testicular endocrine function and the physical, psychic and sexual symptoms of ageing. One of these studies is the Turku Male Ageing Study (TuMAS), conducted in Turku, Finland. This review summarises the recent key findings in this study, with special reference to the correlation of androgen levels with sexual symptoms and cardiovascular risk factors.
\end{abstract}

Key words: Ageing, Atherosclerosis, Coronary heart disease, Late-onset hypogonadism, Lifespan, Longevity, Male ageing, Sexual dysfunction, Testosterone

\section{INTRODUCTION}

The endocrinology of ageing men has recently been under intensive research and numerous large studies are ongoing to delineate the gender-specific aspects of male ageing (Table 1), with special reference to the importance of the well-documented age-related decline of testicular function. Multiple names have been coined to describe the condition, such as male

Address for correspondence:

Professor Ilpo Huhtaniemi, Department of Reproductive

Biology, Imperial College London, Hammersmith Campus,

Du Cane Road, London W12 0NN, UK,

Tel.: +44-20-75942104, Fax: +44-20-75942184

e-mail: ilpo.huhtaniemi@imperial.ac.uk

Received 09-11-07, Revised 10-12-07, Accepted 20-12-07 menopause, viropause, andropause, Partial Androgen Deficiency of the Ageing Man (PADAM) and Late-Onset Hypogonadism ( $\mathrm{LOH}$ ). The last term describes this condition most accurately and is now recommended for general use. ${ }^{1,2} \mathrm{LOH}$ is defined as subnormal serum testosterone $(\mathrm{T})$ levels in connection with an array of physical, psychic and sexual symptoms, generally related to male hypogonadism. These include muscle weakness, decreased lean body mass, increased visceral fat, fatigue, depression, irritability, sleep disturbances, decreased body hair, osteoporosis, diminished libido, weakened morning erections and erectile dysfunction. Indeed, it is well documented that testicular $\mathrm{T}$ production decreases continuously after 40 years of age. ${ }^{3}$ The mean de- 
Table 1. The main, currently ongoing population based studies, addressing the endocrinology of the ageing male.

\begin{tabular}{llc}
\hline Study & \multicolumn{1}{c}{$\begin{array}{c}\text { Relevant Web site } \\
\text { references }\end{array}$} \\
\hline $\begin{array}{l}\text { The Baltimore Longitudinal Study of Aging } \\
\text { The European Male Ageing Study (EMAS) }\end{array}$ & $\begin{array}{l}\text { http://www.grc.nia.nih.gov/branches/blsa/blsa.htm } \\
\text { http://www.emas.man.ac.uk/main.asp } \\
\text { http://www.florey.adelaide.edu.au/reserch.html }\end{array}$ \\
$\begin{array}{ll}\text { The Florey Adelaide Male Ageing Study } \\
\text { The Flemish Male Ageing Studies, Ghent University Hospital }\end{array}$ & http://www.touchbriefings.com/pdf/1711/ACF278D.pdf $\quad 35,36$ \\
The Massachusetts Male Ageing Study (MMAS) & http://www.neriscience.com/web/documents/ \\
& WCMHG\%202007\%20Symposia\%20handout.pdf \\
The Rancho-Bernardo Study & http://www.nia.nih.gov/ResearchInformation/ \\
& ScientificResources/StudyInfo.htm?id=114 \\
The Rotterdam Elderly Study & http://www.epib.nl/ergo.htm \\
The Tromso Study & http://clinicaltrials.gov/ct/show/NCT00119483 \\
The Turku Male Ageing Study (TuMAS) & http://www.uta.fi/laitokset/tsph/itu/huhtaniemi.htm
\end{tabular}

crease in serum total T levels is only small (about $1 \%$ per year between the ages of 40 and 70 years) and shows considerable individual variation. $\mathrm{T}$ levels are therefore likely to reach the hypogonadal range in some ageing men. However, it has proven difficult to demonstrate causality between $\mathrm{T}$ levels and $\mathrm{LOH}$ symptoms in the ageing male population: men with a high symptom score often have normal $\mathrm{T}$ levels, and vice versa. Moreover, these changes do not occur independently of several other age-related changes, including cardiovascular disease, insulin resistance and metabolic syndrome, which can resemble symptoms of hypogonadism either with or without concomitant decline of T. Finally, the levels of hormones other than $\mathrm{T}$ also decrease with age (e.g. growth hormone, insulin-like growth factor-1, thyroid hormone, cortisol, adrenocorticotrophic hormone, dehydroepiandrosterone sulfate and melatonin). ${ }^{4}$

One of the ongoing studies on $\mathrm{LOH}$ is the Turku Male Ageing Study and our purpose herein has been to review some of our recent findings with special reference to the correlation of testicular function with sexual symptoms and cardiovascular risk factor in ageing men.

\section{THE TURKU MALE AGEING STUDY (TuMAS)}

The TuMAS study was initiated in the year 2000 in order to determine the frequency and stability of LOH symptoms and gonadal hormone levels in 4069 year-old men $(n=28,622)$ in the town of Turku in south-western Finland. The study began with the mailing of an epidemiological questionnaire to the men asking them about general well-being and $\mathrm{LOH}$ symptoms. A total of 15,496 (54.1\%) men returned the questionnaire, which was composed of three parts: 1) a simplified Turku 3-question query (T3Q; see below), 2) the 17-question Ageing Male Symptoms (AMS) questionnaire ${ }^{5-7}$ and 3 ) a query about known illnesses and medications, as well as on socio-behavioural factors such as cohabiting, level of education, working status, amount of exercise, smoking, alcohol consumption and life satisfaction. The T3Q query consisted of three questions: During the last 5 years, have you experienced 1) increasing weakness in tasks requiring strength, 2) decreased libido and 3) depression? Men fulfilling the simplified LOH symptom severity criteria ( $\geq 2$ score in T3Q; $n=2,516$ ) were invited to the laboratory for blood sampling to assess their sex hormone and lipid status; 1,619 men (64.3\%) participated. Subsequently, several nested studies have been carried out on all or selected subpopulations of the TuMAS cohort. ${ }^{8-11}$

\section{SEXUAL SYMPTOMS, POOR LIFE SATISFACTION AND INCREASED USAGE OF HEALTH SERVICES ARE ASSOCIATED WITH LOH}

It is generally recognized that androgens, due to their strong anabolic effects, are important not only for the maintenance of male reproductive functions but also for a number of other organ systems such as 
bone, adipose tissue, muscle, haematopoiesis, brain and skin. The typical symptoms of ageing in men are assumed to be caused by the documented decline of $\mathrm{T}$ production with ageing, leading to the array of symptoms of LOH. It has been documented that the threshold of sensitivity of the different organ systems to androgens differs ${ }^{12}$ and, if the same holds true for the case of ageing-associated decline of androgens, then the different types of symptoms of androgen deficiency should occur in predictable order, depending on their thresholds. In one of the TuMAS studies, we monitored the prevalence of the sexual AMS in ageing men, assuming that they might occur earlier than the non-sexual anabolic and psychic effects. The association of these symptoms with general health, health behaviour, life satisfaction and frequency of visits to physicians were correlated.

The severity of sexual symptoms and the total symptom scores measured by the AMS scale increased with age as expected. A hypothetical positive score sum for LOH symptoms $>36^{6,7}$ was observed in $30 \%$ of the respondents. Amongst healthy men, the frequency of high LOH scores was $20 \%$. The AMS scale questions and the distribution of answers for each of the 5-year age-groups are shown in Figures 1 and 2. The greatest changes/deterioration with age (as determined by correlation coefficients) were found in the decrease of muscle strength and the worsening of sexual symptoms, with the latter nearly doubling between the ages of 40-41 and 65-69 years. The frequency of physical symptoms also increased with age, although the age trend was clearly weaker. Mental symptoms (sleep disturbances, increased need of sleep, irritability, nervousness, anxiety, exhaustion) displayed only weak progression until the age of 55 years, after which many of them showed improvement. In general, statistically significant age-related changes occurred in almost all the AMS scale parameters, with the exception of sleeping disturbances and anxiety. The smallest change with age was observed in the reported decrease of beard growth where $93 \%$ of the men observed no change. In contrast, $41 \%$ of the men reported moderate to very clear symptoms in joint and muscle complaints. At least moderate sexual symptoms were reported by $20.4 \%$ of the men aged $40-44$ years, with a linear increase in these symptoms to $67.4 \%$ in the oldest
(65-69 year) age-group.

Multivariate linear regression analyses revealed that increased sexual symptoms were strongly associated with decreased life satisfaction and increased frequency of visits to the physician, independent of the nature of the medical condition. In men with moderate to severe sexual symptoms, visits to the physician were three times more frequent than in men with mild or no symptoms. Age appeared to be the best predictive factor in the development of sexual symptoms, while, for example, the effect of body mass increase did not reach significance. Depression, unemployment, lack of physical activity and to some extent lower education were independent correlates for the LOH score. It appeared evident that of the AMS questions, decreased muscle strength, depression and sexual symptoms accounted for $76.3 \%$ of the total score, which supports the accuracy of the simplified T3Q score. These questions could possibly be utilised as a simple and efficient screening tool for $\mathrm{LOH}$ in daily clinical practice. Sexual symptoms as such deserve more attention in the workup of ageing male patients because they offer a simple screening tool to detect impaired well-being with increased use of health services and may be the first sign of imminent LOH. Curiously, the study of Bhasin et $\mathrm{al}^{12}$ in young men on the different thresholds of the androgen-dependent responses showed that the maintenance of sexual functions required lower androgen levels than that required for the anabolic effects. It is therefore paradoxical that sexual symptoms were in our study the first to appear. This suggests that androgen deficiency is not the main cause of sexual symptoms in ageing men.

\section{CIRCULATING TESTOSTERONE AND SERUM LIPIDS IN AGEING MEN}

Men have higher life-time risk for atherosclerosis than women. ${ }^{13}$ This difference has been ascribed to sex steroids through their direct actions on vascular function and levels on atherosclerotic risk factors. Serum lipoproteins contribute to atherosclerosis, and the sex differences have been attributed a) to differences in lipids, given that the protective factor, HDL-cholesterol, is higher in women, ${ }^{14}$ b) to the beneficial effects of oestrogens and c) to less benefi- 

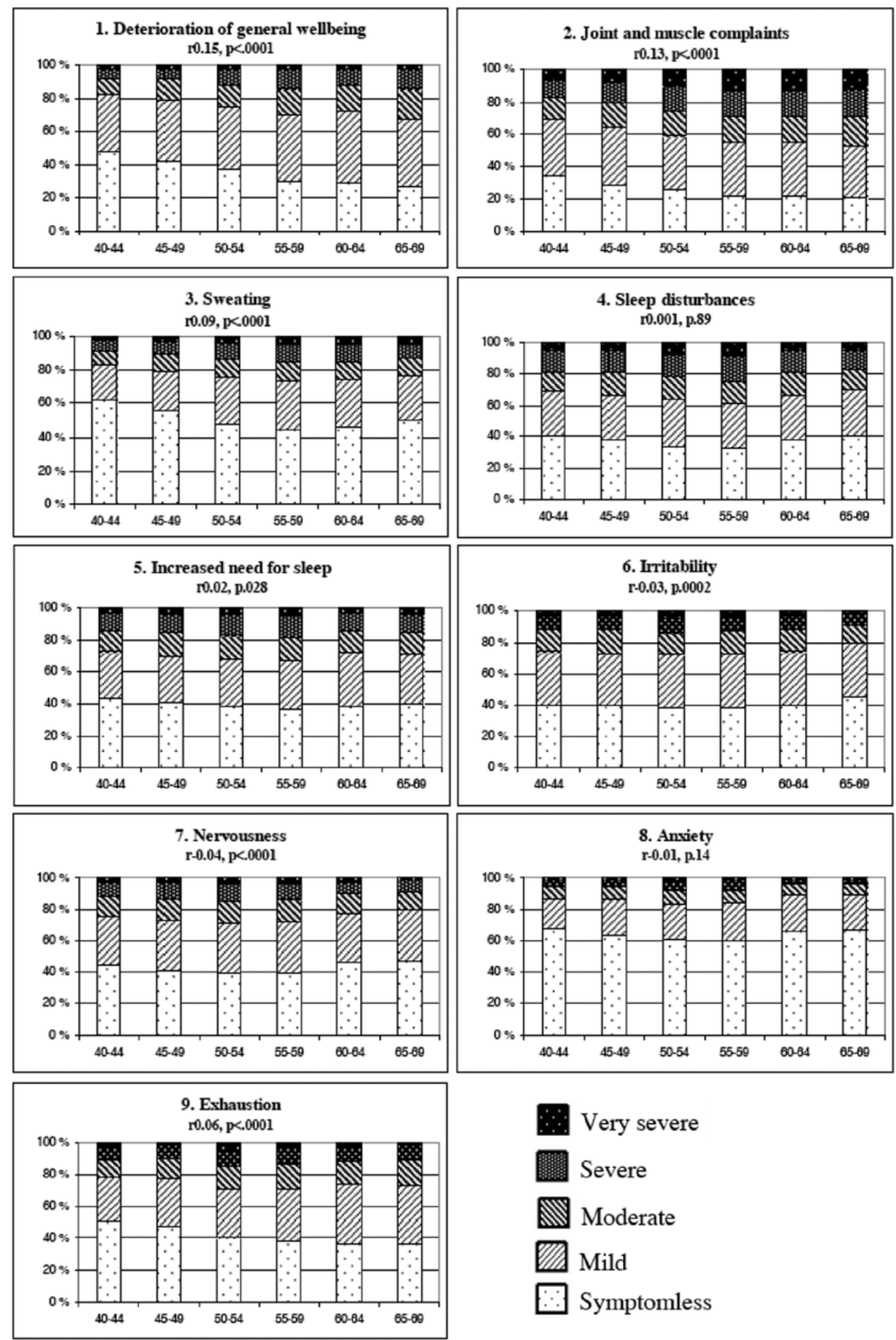

Figure 1. Prevalence of ageing male symptoms in 5-year age groups and Spearman correlation coefficients with age in the TuMAS study. Questions were direct in character, with answers ranging from no symptoms (1 point) through mild (2), moderate (3), severe (4) and very severe (5 points) symptoms. From ref. 10, with permission. 

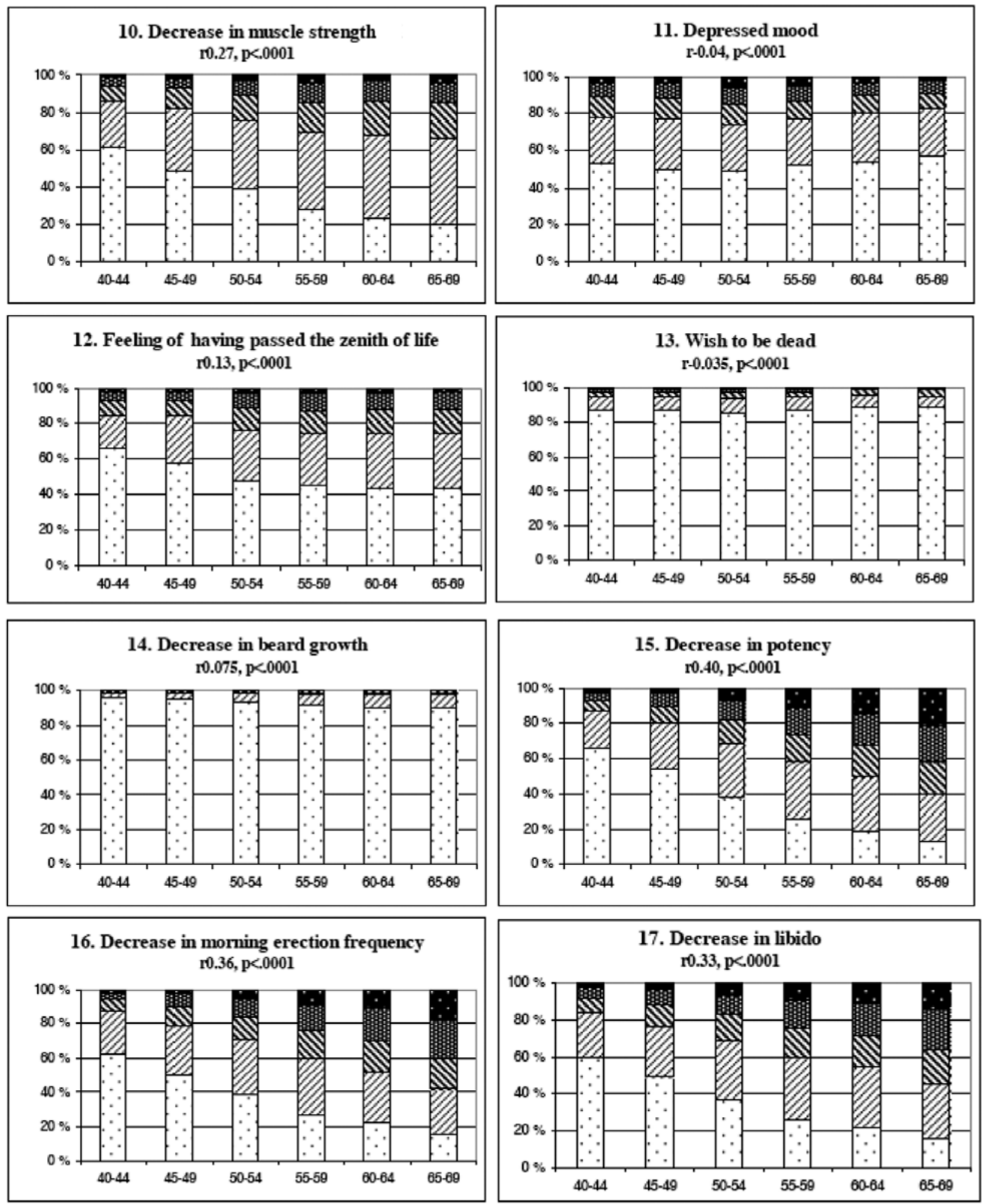

Very severe 10 Severe $\mathbb{W}$ Moderate

Figure 2. Prevalence of ageing male symptoms in 5-year age groups and Spearman correlation coefficients with age in the TuMAS study. Questions were direct in character, with answers ranging from no symptoms (1 point) through mild (2), moderate (3), severe (4) and very severe (5 points) symptoms. From ref. 10, with permission. 
cial effects of androgens which have been observed in HDL-cholesterol levels in both sexes. ${ }^{15,16}$ All in all, the connections of both endogenous levels of $\mathrm{T}$ and $\mathrm{T}$ therapy on blood lipids are complicated and evidence exists in both directions. ${ }^{11,17}$ The association between $\mathrm{T}$ and lipids still lacks strong epidemiological verification. We hypothesised that, in agreement with the increased atherosclerosis in hypoandrogenic men, atherosclerotic alterations could also be found in men with LOH symptoms and decreased T. The objective of the study carried out ${ }^{11}$ was thus to determine the association of sex steroid hormones with serum lipids within a subcohort of the TuMAS men.

The study population consisted of 1,619 men, including those who where originally determined to have a high $\mathrm{LOH}$ symptom score and who came (64\%) to the laboratory to give a blood sample. In a bivariate analysis, $\mathrm{T}$ correlated inversely with BMI, total cholesterol and triglycerides, smoking and Cardiocascular Diseases (CVD) and correlated directly with HDL-cholesterol (Table 2). Alcohol consumption correlated directly with HDL-cholesterol $(r=0.18, p$ $<0.0001)$. In multivariate analysis, when the independent correlates of serum lipids were taken into account (age, BMI, T, smoking, alcohol consumption, CVD and diabetes), $T$ and alcohol consumption appeared as positive and BMI as negative correlates. With regard to triglycerides, BMI and CVD appeared as positive and age and $\mathrm{T}$ as negative correlates. In further analyses, the associations between $\mathrm{T}$ and triglycerides and

Table 2. Spearman's correlation coefficients between testosterone and other study variables in 1,619 ageing men in the TuMAS Study. ${ }^{11}$

\begin{tabular}{lcc}
\hline Variable & $r$ & $p$-value \\
\hline Age & -0.04 & 0.13 \\
BMI & -0.34 & $<0.0001$ \\
Total cholesterol & -0.06 & 0.025 \\
HDL-cholesterol & 0.24 & $<0.0001$ \\
LDL-cholesterol & 0.05 & 0.09 \\
Triglycerides & $-0-30$ & $<0.0001$ \\
CVD & -0.13 & $<0.0001$ \\
Diabetes & 0.005 & 0.85 \\
Smoking & -0.05 & 0.02 \\
Alcohol consumption & 0.02 & 0.34 \\
The Turku 3Q scale & -0.008 & 0.75 \\
The AMS scale & -0.03 & 0.26 \\
\hline
\end{tabular}

HDL-cholesterol were independent of BMI, and the independent positive correlates for HDL-cholesterol appeared to be $\mathrm{T}$ and alcohol consumption, whereas the correlation with BMI was negative.

Hence, these data showed that low $\mathrm{T}$ in ageing men is independently associated with adverse lipid profile, including low HDL-cholesterol and high triglycerides. These results provide evidence that negative influence of $\mathrm{T}$ on blood lipids is not responsible for the higher risk of atherosclerosis and CVD in ageing men. In fact, higher T levels seem to be associated with favourable lipid profiles. Moreover, there also seems to exist an independent favourable component in the effect of $\mathrm{T}$ on blood lipids that is not dependent on BMI. Beneficial effects of $T$ on insulin sensitivity may at least partly explain this independent effect. ${ }^{17}$

The mechanisms responsible for the increased incidence of CVD in men still remain inadequately understood. It seems that sex hormones have a gender-specific effect on atherosclerotic risk factors. According to this study, low serum $\mathrm{T}$ concentration in middle-aged and ageing men was associated with an atherogenic risk profile including obesity, low HDL-cholesterol and increased triglycerides. These results provide evidence that low plasma $\mathrm{T}$ in ageing men is associated with increased risk of atherosclerosis also independent of overweight. However, a recent meta-analysis indicated that $\mathrm{T}$ supplementation of men may induce reductions in both total cholesterol and HDL-cholesterol concentrations. ${ }^{18}$ One possible caveat of $\mathrm{T}$ treatment is thus the possibility that it may only reverse a biochemical parameter (serum $\mathrm{T}$ ) that is a consequence of the protective mechanisms against the stress of disease, such as atherosclerosis. It would therefore sound more reasonable to treat the causes of lower $\mathrm{T}$ than to pharmacologically reverse a parameter indicative of imbalanced homeostasis. However, the current data are still insufficient for final conclusions. In any case, we may safely conclude that high physiological $\mathrm{T}$ levels are not associated with increased CVD risk in ageing men.

\section{INCREASED CAROTID ATHEROSCLEROSIS IN MEN WITH SYMPTOMS OF LATE-ONSET HYPOGONADISM}

We further evaluated the association of ageing male sex hormone levels with the risk of CVD. ${ }^{8}$ 
Another subgroup of the TuMAS men were studied for carotid artery intima-media thickness (IMT), a widely accepted noninvasive measure of preclinical atherosclerosis and a predictor of future adverse cardiovascular and cerebrovascular events. ${ }^{19,20}$ Some previous observations have suggested that carotid IMT may be inversely associated with serum $\mathrm{T}$ levels in very old men ${ }^{21}$ and in men with type 2 diabetes ${ }^{22}$ and obesity. ${ }^{23}$ A recent study showed inverse association of serum $\mathrm{T}$ with the progression of carotid atherosclerosis in elderly men. ${ }^{24} \mathrm{We}$ therefore examined the hypothesis that androgen deficiency in ageing men is a risk factor for the development of atherosclerosis and examined the relationship of $\mathrm{LOH}$ with cardiovascular risk factors and carotid IMT in a randomly selected subpopulation of 239 men from the TuMAS cohort.

Of the original TuMAS population with $\mathrm{LOH}$, i.e. high symptom score and serum $\mathrm{T}<9.8 \mathrm{nmol} / \mathrm{L}$, or serum $\mathrm{T}>9.8 \mathrm{nmol} / \mathrm{l}$ but serum LH $>6 \mathrm{IU} / \mathrm{l}$ (considered compensated or preclinical hypogonadism), 99 had no clinical manifestations of CVD and had not been previously diagnosed with hypertension or diabetes. These men were invited to the study (3 of them were subsequently excluded because of newly diagnosed type 2 diabetes). In addition, another 200 men with a normal $\mathrm{T}$ and low LOH symptom score were invited as controls; 140 arrived. Carotid IMT was determined by high-resolution B-mode ultrasound. The hormonal parameters measured were serum $\mathrm{T}$, oestradiol, LH and sex-hormone-binding globulin, while the serum lipid profile was also determined.

We found that both the values of maximum common carotid IMT $(1.08 \pm 0.34$ vs $1.00 \pm 0.23 \mathrm{~mm}$; mean \pm SD) and of maximum IMT of the carotid bulb $(1.44 \pm 0.48$ vs $1.27 \pm 0.35 \mathrm{~mm})$ were higher in $\mathrm{LOH}$ men than in controls. Carotid IMT was inversely associated with serum T (Figure 3 ) and the HDL/total cholesterol ratio and it correlated positively with $\mathrm{LH}$ (Figure 3), age, blood pressure, BMI, total cholesterol and LDL-cholesterol. In the stepwise multivariate regression model, the independent explanatory variables for carotid IMT were age, total cholesterol, T, $\mathrm{LH}$ and smoking. When the group variable for $\mathrm{LOH}$ was included in the multivariate model instead of $\mathrm{T}$ and $\mathrm{LH}$, the significant explanatory variables for the maximum common carotid ITM were the group variable, age, total cholesterol and smoking. Free androgen index, when substituted for T, was not associated with ITM in the multivariate model.

These results show that hypogonadal status (both absolute and preclinical), along with a high $\mathrm{LOH}$ symptom score, is associated with increased carotid artery IMT, providing a marker for subclinical atherosclerosis in middle-aged men. Moreover, T was inversely and LH directly associated with IMT after
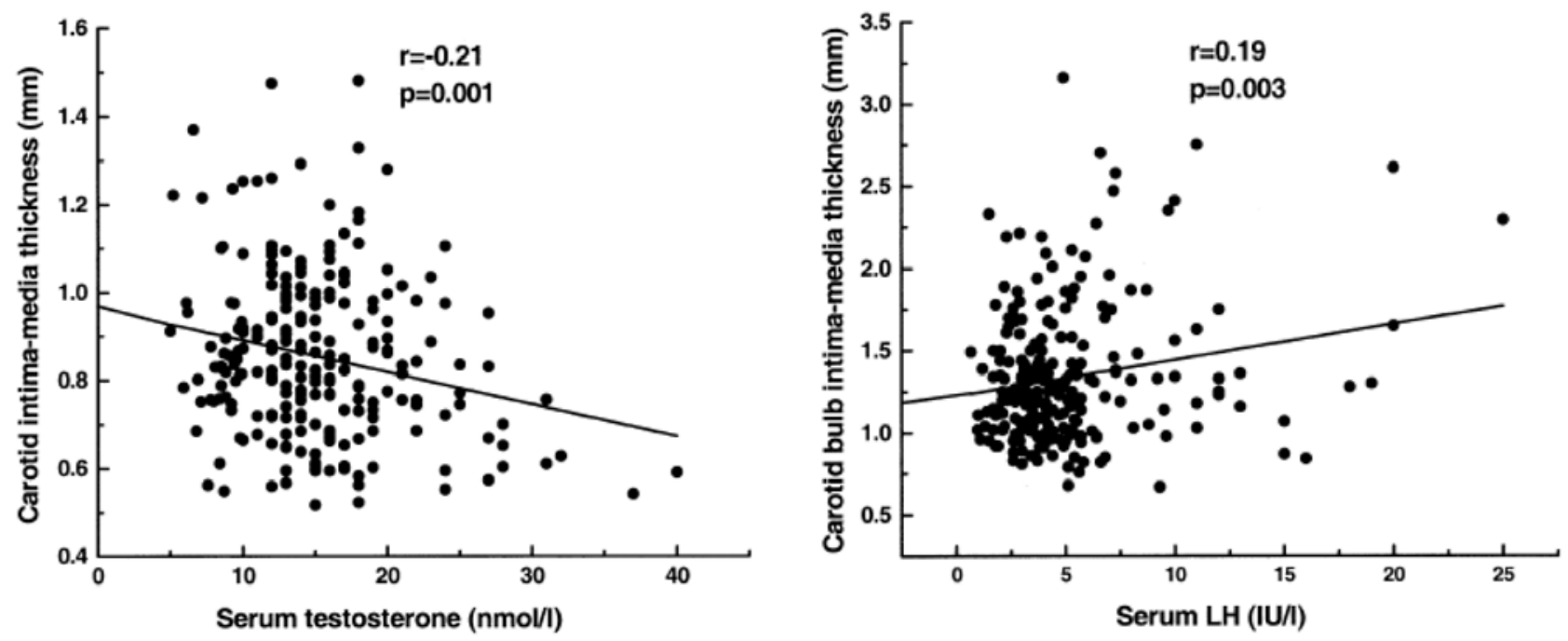

Figure 3. Correlations between serum T (left panel) and LH (right panel) and maximum intima-media thickness of the carotid and carotid bulb, respectively, in 236 middle-aged men. From ref. 8, with permission. 
controlling for CVD risk factors in the multivariate model. Low T indicates absolute hypogonadism, and elevated LH together with low normal T indicates the subclinical form, as observed by us in another study on the TuMAS subjects. ${ }^{9}$ Also, other recent studies on carotid IMT have shown inverse associations between serum $\mathrm{T}$ levels in elderly men of 72 to 92 years of age, ${ }^{21}$ in men with type 2 diabetes ${ }^{22}$ and in obese men with glucose intolerance..$^{23}$ Another large population-based study ${ }^{25}$ has shown that serum T levels inversely and independently correlate with the presence of calcified aortic plaques and the progression of aortic atherosclerosis. The findings of our study are in line with and extend the findings of the previous studies on the inverse association of T and IMT in middle-aged men. The causality of the association needs to be studied in prospective studies, but the currently available information suggests that normal androgen levels protect ageing men from developing atherosclerosis. It is possible that the interaction is bi-directional: on the one hand low $\mathrm{T}$ is a sensitive sign of a subclinical condition, but conversely high T may have independent positive protective effects, e.g. by increasing insulin sensitivity. ${ }^{17}$ Other possible effects may include the anti-inflammatory effect of sex hormones, regulation of apoptosis and promotion of smooth muscle cell stability. ${ }^{26}$ It is also possible that the causative hormone is not $\mathrm{T}$ but its metabolite oestradiol; men with higher $\mathrm{T}$ levels are bound to also have higher levels of oestrogens. In the study of Alevizaki et al, ${ }^{27}$ it was found that men with shorter androgen receptor CAG microsatellite repeats had more severe CVD, as monitored by the number of arteries with severe stenosis in the coronary arteriography, than men with longer repeats. Although there was no correlation between CAG repeat length and $\mathrm{T}$, such direct correlation was found with oestradiol. Hence, T may in this case function as the pro-hormone for the cardioprotective oestrogen.

Our results raise the possibility that individuals with LOH symptoms, together with impaired androgen status and increased IMT, might benefit from T replacement therapy to decelerate the progression of atherosclerosis and to protect them from clinical consequences (i.e. CVD, ischemic stroke and peripheral vascular disease). The ultrasound measurement of carotid IMT could provide an additional predictive tool for decision-making in CVD risk stratification. However, randomized controlled trials are required to establish the effect of $\mathrm{T}$ supplementation on the occurrence of CVD in men suffering from $\mathrm{LOH}$ before wide-scale use of these regimens can be accepted for the prevention of atherosclerotic diseases.

\section{CONCLUSIONS}

Several major questions about the importance of the ageing-related decline of $\mathrm{T}$ production still remain unanswered. In particular, the poor correlation of low $\mathrm{T}$ levels and $\mathrm{LOH}$ symptoms remains a conundrum and raises the question as to whether we use the right methods to assess the androgen status of ageing men. Although the clinical immunoassay methods used for $\mathrm{T}$ measurement have recently been under criticism, ${ }^{28,29}$ this mainly applies to the low levels detected in children and women. The T levels in ageing men, even after their expected suppression, are still high enough to be in the reliable range of the immunoassays. It remains to be seen if the novel in vitro bioassays ${ }^{30}$ that monitor the total androgen bioactivity in serum would provide better correlation between LOH symptoms and T levels. Another possibility is that the declining $\mathrm{T}$ levels are only a minor determinant of LOH symptoms, so that for these biological reasons better correlation cannot even be expected. Our quest for better biomarkers of male ageing must therefore continue. What the results from the TuMAS study have shown is that increased incidence of sexual problems in ageing men may be the most sensitive prodromal symptom for imminent LOH. Enquiry about them should be included in the questions the physician routinely asks of an ageing male patient. Furthermore, the Turku data show that, unlike some previous contentions, high $\mathrm{T}$ levels in ageing men are not a risk factor for atherosclerosis. In contrast, preclinical atherosclerotic findings are associated with low T levels, while a part of the positive androgen effects seems to be due to direct actions of $\mathrm{T}$ or its metabolite oestradiol.

\section{REFERENCES}

1. Nieschlag E, Swerdloff R, Behre HM, et al, 2005 Investigation, treatment and monitoring of late-onset hypogonadism in males: ISA, ISSAM, and EAU recommendations. J Androl 27: 135-137. 
2. Perheentupa A, Huhtaniemi I, 2007 Does the andropause exist? Nat Clin Pract Endocrinol Metab 3: 670-671.

3. Kaufman JM, Vermeulen A, 2005 The decline of androgen levels in elderly men and its clinical and therapeutic implications. Endocr Rev 26: 833-876.

4. Lamberts SW, van den Beld AW, van der Lely AJ, 1997 The endocrinology of aging. Science 278: 419-424.

5. Ichioka K, Nishiyama H, Yoshimura K, Itoh N, Okubo K, Terai A, 2006 Aging Males' Symptoms scale in Japanese men attending a multiphasic health screening clinic. Urology 67: 589-593.

6. Heinemann LA, Saad F, Zimmermann T, et al, 2003 The Aging Males' Symptoms (AMS) scale: Update and compilation of international versions. Health Qual Life Outcomes 1: 15.

7. Heinemann LA, Saad F, Heinemann K, Thai DM, 2004 Can results of the Aging Males' Symptoms (AMS) scale predict those of screening scales for androgen deficiency? Aging Male 7: 211-218.

8. Makinen J, Jarvisalo MJ, Pollanen P, et al, 2005 Increased carotid atherosclerosis in andropausal middle-aged men.

J Am Coll Cardiol 45: 1603-1608.

9. Harkonen K, Huhtaniemi I, Makinen J, et al, 2003 The polymorphic androgen receptor gene CAG repeat, pituitary-testicular function and andropausal symptoms in ageing men. Int J Androl 26: 187-194.

10. Mäkinen JI, Perheentupa A, Raitakari OT, et al, 2007 Sexual symptoms in aging men indicate poor life satisfaction and increased health service consumption. Urology 70: 1194-1199.

11. Mäkinen JI, Perheentupa A, Irjala K, et al, 2007 Endogenous testosterone and serum lipids in middle-aged men. Atherosclerosis [Epub ahead of print]

12. Bhasin S, Woodhouse L, Casaburi R, et al, 2001 Testosterone dose-response relationships in healthy young men. Am J Physiol Endocrinol Metab 281: E1172-1181.

13. Tunstall-Pedoe H, Kuulasmaa K, Amouyel P, Arveiler D, Rajakangas AM, Pajak A, 1994 Myocardial infarction and coronary deaths in the World Health Organization MONICA Project. Registration procedures, event rates, and case-fatality rates in 38 populations from 21 countries in four continents. Circulation 90: 583-612.

14. Carlson LA, Ericsson M, 1975 Quantitative and qualitative serum lipoprotein analysis. Part 1 . Studies in healthy men and women. Atherosclerosis 21: 417-433.

15. Bradley DD, Wingerd J, Petitti DB, Krauss RM, Ramcharan S, 1978 Serum high-density-lipoprotein cholesterol in women using oral contraceptives, estrogens and progestins. N Engl J Med 299: 17-20.

16. Wallentin L, Varenhorst E, 1978 Changes of plasma lipid metabolism in males during estrogen treatment for prostatic carcinoma. J Clin Endocrinol Metab 47: 596-599.

17. Wu FC, von Eckardstein A, 2003 Androgens and coronary artery disease. Endocr Rev 24: 183-217.

18. Isidori AM, Giannetta E, Greco EA, et al, 2005 Effects of testosterone on body composition, bone metabolism and serum lipid profile in middle-aged men: a meta-analysis. Clin Endocrinol (Oxf) 63: 280-293.

19. Salonen JT, Salonen R, 1991 Ultrasonographically assessed carotid morphology and the risk of coronary heart disease. Arterioscler Thromb 11: 1245-1249.

20. O'Leary DH, Polak JF, Kronmal RA, Manolio TA, Burke GL, Wolfson SK, Jr, 1999 Carotid-artery intima and media thickness as a risk factor for myocardial infarction and stroke in older adults. Cardiovascular Health Study Collaborative Research Group. N Engl J Med 340: 14-22.

21. van den Beld AW, Bots ML, Janssen JA, Pols HA, Lamberts SW, Grobbee DE, 2003 Endogenous hormones and carotid atherosclerosis in elderly men. Am J Epidemiol 157: 25-31.

22. Fukui M, Kitagawa Y, Nakamura N, et al, 2003 Association between serum testosterone concentration and carotid atherosclerosis in men with type 2 diabetes. Diabetes Care 26: 1869-1873.

23. De Pergola G, Pannacciulli N, Ciccone M, Tartagni M, Rizzon P, Giorgino R, 2003 Free testosterone plasma levels are negatively associated with the intima-media thickness of the common carotid artery in overweight and obese glucose-tolerant young adult men. Int J Obes Relat Metab Disord 27: 803-807.

24. Muller M, van den Beld AW, Bots ML, Grobbee DE, Lamberts SW, van der Schouw YT, 2004 Endogenous sex hormones and progression of carotid atherosclerosis in elderly men. Circulation 109: 2074-2079.

25. Hak AE, Witteman JC, de Jong FH, Geerlings MI, Hofman A, Pols HA, 2002 Low levels of endogenous androgens increase the risk of atherosclerosis in elderly men: the Rotterdam Study. J Clin Endocrinol Metab 87: 3632-3639.

26. Malkin CJ, Pugh PJ, Jones RD, Jones TH, Channer KS, 2003 Testosterone as a protective factor against atherosclerosis--immunomodulation and influence upon plaque development and stability. J Endocrinol 178: 373-380.

27. Alevizaki M, Cimponeriu AT, Garofallaki M, et al, 2003 The androgen receptor gene CAG polymorphism is associated with the severity of coronary artery disease in men. Clin Endocrinol 59: 749-755.

28. Wang C, Catlin DH, Demers LM, Starcevic B, Swerdloff RS, 2004 Measurement of total serum testosterone in adult men: comparison of current laboratory methods versus liquid chromatography-tandem mass spectrometry. J Clin Endocrinol Metab 89: 534-543.

29. Matsumoto AM, Bremner WJ, 2004 Serum testosterone assays--accuracy matters. J Clin Endocrinol Metab 89: 520-524.

30. Roy P, Alevizaki M, Huhtaniemi I, 2008 In vitro bioassays for androgens and their diagnostic applications. Hum Reprod Update 14: 73-82.

31. Parsons JK, Carter HB, Platz EA, Wright EJ, Landis P, Metter EJ, 2005 Serum testosterone and the risk of prostate cancer: potential implications for testosterone 
therapy. Cancer Epidemiol Biomarkers Prev 14: 22572260.

32. Parsons JK, Carter HB, Partin AW, et al, 2006 Metabolic factors associated with benign prostatic hyperplasia. $\mathbf{J}$ Clin Endocrinol Metab 91: 2562-2568.

33. Martin SA, Haren MT, Middleton SM, Wittert GA, 2007 The Florey Adelaide Male Ageing Study (FAMAS): design, procedures \& participants. BMC Public Health 7: 126.

34. Martin DM, Wittert G, Burns NR, Haren MT, Sugarman R, 2007 Testosterone and cognitive function in ageing men: data from the Florey Adelaide Male Ageing Study (FAMAS). Maturitas 57: 182-194.

35. Lapauw B, Goemaere S, Crabbe P, Kaufman JM, Ruige $\mathrm{JB}, 2007$ Is the effect of testosterone on body composition modulated by the androgen receptor gene CAG repeat polymorphism in elderly men? Eur J Endocrinol 156: 395-401.

36. Crabbe P, Bogaert V, De Bacquer D, Goemaere S, Zmierczak H, Kaufman JM, 2007 Part of the interindividual variation in serum testosterone levels in healthy men reflects differences in androgen sensitivity and feedback set point: contribution of the androgen receptor polyglutamine tract polymorphism. J Clin Endocrinol Metab 92: 3604-3610.

37. O'Donnell AB, Araujo AB, McKinlay JB, 2004 The health of normally aging men: The Massachusetts Male Aging Study (1987-2004). Exp Gerontol 39: 975-984.
38. Araujo AB, O’Donnell AB, Brambilla DJ, et al, 2004 Prevalence and incidence of androgen deficiency in middle-aged and older men: estimates from the Massachusetts Male Aging Study. J Clin Endocrinol Metab 89: 5920-5926.

39. Morton DJ, Kritz-Silverstein D, Riley DJ, Barrett-Connor EL, Wingard DL, 2007 Premature graying, balding, and low bone mineral density in older women and men: the Rancho Bernardo Study. J Aging Health 19: 275-285.

40. Laughlin GA, Barrett-Connor E, May S, 2006 Sex-specific association of the androgen to oestrogen ratio with adipocytokine levels in older adults: the Rancho Bernardo Study. Clin Endocrinol 65: 506-513.

41. Hofman A, Breteler MM, van Duijn CM, et al, 2007 The Rotterdam Study: objectives and design update. Eur J Epidemiol 22: 819-829.

42. Yazdanpanah N, Zillikens MC, Rivadeneira F, et al, 2007 Effect of dietary B vitamins on BMD and risk of fracture in elderly men and women: the Rotterdam study. Bone 41: 987-994.

43. Svartberg J, Jorde R, 2007 Endogenous testosterone levels and smoking in men. The fifth Tromso Study. Int J Androl 30: 137-143.

44. Agledahl I, Skjaerpe PA, Hansen JB, Svartberg J, 2007 Low serum testosterone in men is inversely associated with non-fasting serum triglycerides: The Tromso Study. Nutr Metab Cardiovasc Dis : Jun 7 [Epub ahead of print] 